\title{
The more you judge the worse you feel. A judgemental attitude towards one's inner experience predicts depression and anxiety
}

\author{
Barbara Barcaccia ${ }^{\mathrm{a}, \mathrm{b}, *}$, Roberto Baiocco ${ }^{\mathrm{a}}$, Andrea Pozza ${ }^{\mathrm{c}}$, Susanna Pallini ${ }^{\mathrm{d}}$, Francesco Mancini ${ }^{\mathrm{b}, \mathrm{e}}$, \\ Marco Salvati $^{\mathrm{a}}$
}

a Department of Developmental and Social Psychology, Sapienza University of Rome, Italy

${ }^{\mathrm{b}}$ Associazione di Psicologia Cognitiva APC and Scuola di Psicoterapia Cognitiva srl SPC, Rome, Italy

${ }^{\mathrm{c}}$ Department of Health Sciences, University of Florence, Italy

d Department of Education, Roma Tre University, Italy

e Guglielmo Marconi University, Rome, Italy

\section{A R T I C L E I N F O}

\section{Keywords:}

Mindfulness

Acceptance

Judgemental attitude

Depression

Anxiety

Worry

Rumination

\begin{abstract}
A B S T R A C T
Literature reviews have shown that trait-mindfulness is significantly correlated to emotional wellbeing, both in adults and in children. Particularly, being judgemental towards one's inner thoughts, feelings and sensations, and acting unawares, is associated with higher maladjustment.

In the present cross-sectional study, we explored the role of the different facets of mindfulness in both anxiety and depression, controlling for the effects of gender, age, rumination, and worry, and analysed which facets of mindfulness have the strongest effect in predicting depression and anxiety. Two-hundred seventy-four community adults were assessed in the domains of depression, anxiety, rumination, worry, and mindfulness. Regression analyses showed that, among the facets of mindfulness, a judgemental attitude towards one's thoughts and feelings is the strongest predictor of both depression and anxiety. Our study highlights the importance of a normalising, accepting, non-judgemental attitude to decrease anxiety and depression, and to foster wellbeing.
\end{abstract}

\section{Introduction}

Mindfulness was first applied to Western medicine back in the '80s, mainly to patients who suffered from various organic illnesses, with a program aiming at tackling stress, disability and pain (Kabat-Zinn, 1982). Jon Kabat-Zinn, who introduced mindfulness practices in Western health system, defined mindfulness as the process of "paying attention in a particular way: on purpose, in the present moment, and nonjudgmentally" (Kabat-Zinn, 1994, p. 4). Being mindful means being aware of both the external and internal stimuli, and wittingly re-direct one's attention to the present moment, so that one is neither overwhelmed by the vehemence of thoughts, emotions and sensations, nor led in one's actions and choices by those cognitive contents and affects. Several different definitions of mindfulness share one common element: the non-judgemental attitude towards one's inner experience (Baer, 2003; Hayes \& Greco, 2008; Jennings \& Apsche, 2013).

Trait or dispositional mindfulness should be distinguished from mindfulness resulting from formal mindfulness training, as included in mindfulness-based interventions (MBIs) (Brown \& Ryan, 2003). A mindful disposition may be present in individuals to a greater or lesser extent regardless of formal meditation practice. Evidently, the various practices of mindfulness can enhance the individual's capacity of decentring from one's inner experiences, and of being non-judgemental about them. As a consequence, one's behaviours and actions will be more aware and less determined by automatic patterns of reaction (Baer, 2003; Shapiro, Carlson, Astin, \& Freedman, 2006).

Several studies have shown that trait mindfulness is significantly correlated to emotional wellbeing (Bränström, Duncan, \& Moskowitz, 2011; Kong, Wang, \& Zhao, 2014; Malinowski \& Lim, 2015) and evidenced how MBIs may improve mental health symptomatology both in adults (Gu, Strauss, Bond, \& Cavanagh, 2015; Hofmann, Sawyer, Witt, \& Oh, 2010; van der Velden et al., 2015) and in children/adolescents (Kallapiran, Koo, Kirubakaran, \& Hancock, 2015). Particularly, being judgemental towards one's inner thoughts, feelings and sensations, and acting unawares, is associated with higher psychiatric symptomatology (Baer, Smith, Hopkins, Krietemeyer, \& Toney, 2006). Individuals who tend to adopt a non-judgemental stance towards their own thoughts and feelings have lower depression and anxiety (Barnhofer, Duggan, \&

\footnotetext{
* Corresponding author at: Department of Developmental and Social Psychology, Sapienza University of Rome, Via dei Marsi 78, 00185 Rome, Italy.

E-mail address: barbara.barcaccia@uniroma1.it (B. Barcaccia).
} 
Griffith, 2011; Cash \& Whittingham, 2010; Christopher, Neuser, Michael, \& Baitmangalkar, 2012; Kopala-Sibley, Zuroff, Hankin, \& Abela, 2015).

Mindfulness has been found to be associated with both rumination and worry, two specific cognitive processes representing significant maintenance factors of depression and anxiety (Desrosiers, Vine, Klemanski, \& Nolen-Hoeksema, 2013). Rumination is characterised by passive and repetitive focussing on symptoms of distress, and on the possible causes and consequences of these symptoms (Nolen-Hoeksema, Wisco, \& Lyubomirsky, 2008). Worry has been defined as a form of apprehensive expectation of possible negative outcomes in future events (Borkovec, Robinson, Pruzinsky, \& DePree, 1983). Both worry and rumination have been proven to be significantly associated to depression and anxiety in cross-sectional and in experimental studies (Muris, Roelofs, Rassin, Franken, \& Mayer, 2005; Nolen-Hoeksema, 2000). It has been hypothesised that trait mindfulness helps individuals break their habitual ruminative cycles by making them aware of their feelings and thoughts without judging them or getting trapped in them (Nolen-Hoeksema et al., 2008). Other authors have suggested that the mindful attention to the present moment and the ability to control the focus of attention more broadly would prevent the individual from becoming mired in ruminative thoughts (Baer, 2003; Teasdale, Segal, \& Williams, 1995). However, correlational research has produced mixed findings about the relation between trait mindfulness and rumination: some studies indicate that trait mindfulness, particularly Non-reacting, Acting-with-awareness, and Non-judging, are associated with less rumination (Coffey, Hartman, \& Fredrickson, 2010; Desrosiers et al., 2013; Dundas, Vøllestad, Binder, \& Sivertsen, 2013; Raes \& Williams, 2010); other studies show a positive association between rumination and $\mathrm{Ob}$ serving (Petrocchi \& Ottaviani, 2016; Royuela-Colomer \& Calvete, 2016).

The application of mindfulness has been proven effective in reducing anxiety and depression, as evidenced by several meta-analyses conducted in non-clinical and clinical samples (Hofmann et al., 2010; Khoury et al., 2013; Khoury, Sharma, Rush, \& Fournier, 2015; Warren et al., 2016). MBIs significantly reduce rumination and worry (Delgado et al., 2010; Jain et al., 2007; Singh \& Gorey, 2017). Cognitive treatments for depression which include MBIs enhance mindfulness, which, in turn, is associated with decreases in rumination and depression (Kumar, Feldman, \& Hayes, 2008).

\subsection{Rationale and objectives of the current study}

The role or rumination and worry as cognitive factors associated with depression and anxiety is well-established in the literature (e.g., Muris et al., 2005). The available research has documented well the relation between trait mindfulness and depression or anxiety, evidencing a specific role of Non-judging and Acting-with-awareness (e.g., Barnhofer et al., 2011). However, little is known about the predictive role of trait mindfulness on depression or anxiety controlling for the effects of rumination and worry.

In the present study, we explored the role of the different facets of mindfulness in both anxiety and depression controlling for the effects of gender, age, rumination, and worry, and analysed which facets of mindfulness would have the strongest effect in predicting depression and anxiety. Moreover, we expected that rumination and worry would play a role in the prediction of anxiety and depression. Specifically, we expected that the higher rumination and worry, the higher depression and anxiety would be (Christopher et al., 2012).

\section{Methods}

\subsection{Procedure}

This study involved human participants and was conducted in accordance with the requirements of privacy and informed consent laid down by the Italian law (Law Decree DL-196/2003). Moreover, the study adhered to the latest version of the Declaration of Helsinki revised in Fortaleza (World Medical Association [WMA], 2013) and was approved by the Department of Developmental and Social Psychology (Sapienza University of Rome) Research Ethics Committeee. The questionnaire for this study was part of a larger survey, and its completion required 30-40 min. We employed a convenience sample, with an online survey and snowball recruitment. Participation in the study was voluntary and no compensation was offered to participants. The online survey was created using QuestionPro, a secure data-tracking commercial Web site designed specifically for research purposes (QuestionPro Inc., Seattle, WA). Prior to starting the survey, potential participants read information about the nature of the study and were asked to provide consent to participate in the study by clicking on the "agree" button. Participants were asked to provide demographic information and to answer to a battery of questionnaires.

\subsection{Participants}

Two hundred and seventy-six Italian men $(n=81 ; 29.4 \%)$ and women ( $n=195 ; 70.6 \%)$ were included in the study. The inclusion criteria were: (a) Italian nationality; (b) Being over 18 years old; (c) Having completed all the questionnaires. Data regarding anxiety and depression scores were checked for outliers, and two participants were excluded because their BDI score was 3 standard deviations above the mean. Thus, the final sample consisted of 274 participants with age ranging from 18 to 74 years (men: $M_{\text {age }}=36.19, S D=11.23$; women: $M_{\text {age }}=33.79 ; S D=9.76$; total sample: $M_{\text {age }}=34.50 ; S D=10.25$ ). A more detailed description of the sample is provided in Table 1.

Table 1

Descriptive analysis of the sample (means, standard deviations, frequencies and percentages), divided by gender.

\begin{tabular}{|c|c|c|c|}
\hline \multirow{3}{*}{$\begin{array}{l}\text { Descriptive analysis of the } \\
\text { sample }\end{array}$} & \multicolumn{3}{|c|}{ Total, male and female participants } \\
\hline & Total sample & Men & Women \\
\hline & $N=274$ & $N=81$ & $N=193$ \\
\hline Age & $\begin{array}{l}34.50 \\
(10.25)\end{array}$ & $\begin{array}{l}36.19 \\
(11.23)\end{array}$ & 33.79 (9.76) \\
\hline \multicolumn{4}{|l|}{ Education level } \\
\hline Middle school & $11(4.0 \%)$ & $4(4.9 \%)$ & $7(3.6 \%)$ \\
\hline High school & $76(27.7 \%)$ & $30(37.0 \%)$ & $46(23.8 \%)$ \\
\hline Bachelor degree & $43(15.7 \%)$ & $13(16.0 \%)$ & $30(15.5 \%)$ \\
\hline Master degree & $92(33.6 \%)$ & $21(25.9 \%)$ & $71(36.8 \%)$ \\
\hline Postgraduate level & $52(19.0 \%)$ & $13(16.0 \%)$ & $39(20.2 \%)$ \\
\hline \multicolumn{4}{|l|}{ Civil status } \\
\hline Single & $75(27.4 \%)$ & $24(29.6 \%)$ & $51(26.4 \%)$ \\
\hline Engaged & $79(28.8 \%)$ & $20(24.7 \%)$ & $59(30.6 \%)$ \\
\hline Married/Cohabitants & $103(37.6 \%)$ & $29(35.8 \%)$ & $74(38.3 \%)$ \\
\hline Separated/Divorced & $15(5.5 \%)$ & $8(9.9 \%)$ & $7(3.6 \%)$ \\
\hline Widowers & $2(0.7 \%)$ & $0(0.0 \%)$ & $2(1.0 \%)$ \\
\hline \multicolumn{4}{|l|}{ BDI } \\
\hline Low depression score $(<19)$ & $237(85.5 \%)$ & $71(87.7 \%)$ & $166(86.0 \%)$ \\
\hline $\begin{array}{l}\text { Moderate depression score } \\
\quad(20-30)\end{array}$ & $30(10.9 \%)$ & $8(9.9 \%)$ & $22(11.4 \%)$ \\
\hline High depression score $(>30)$ & $7(2.6 \%)$ & $2(2.5 \%)$ & $5(2.6 \%)$ \\
\hline \multicolumn{4}{|l|}{ STAI-Y } \\
\hline Low anxiety score $(<38)$ & $84(30.7 \%)$ & $55(28.5 \%)$ & $29(35.8 \%)$ \\
\hline $\begin{array}{l}\text { Moderate anxiety score } \\
(38-49)\end{array}$ & $107(39.1 \%)$ & $74(38.3 \%)$ & $33(40.7 \%)$ \\
\hline High anxiety score $(>49)$ & $83(30.3 \%)$ & $64(33.2 \%)$ & $19(23.5 \%)$ \\
\hline
\end{tabular}

Note. Standard deviations and percentages are in parentheses. Means and $N$ are out of parentheses.

BDI groups were created according to the cut-off score (Beck, Steer, \& Carbin, 1988).

STAI-Y groups were created by using the 33,3 and 66,6 percentiles as cut-off points. 


\subsection{Measures}

\subsubsection{Five Facet Mindfulness Questionnaire (FFMQ, Baer et al., 2006)}

The FFMQ consists of 39 items, all rated on a Likert scale ranging from 1 (never or very rarely true) to 5 (very often or always true). The five facets of mindfulness explored with the FFMQ are a) Observing: observing, noticing, thoughts, emotions and sensations (sample item: "I notice the smells and aromas of things"); b) Describing: describing or being capable of labelling with words one's inner experience (sample item: "I'm good at finding words to describe my feelings"); c) Actingwith-awareness: acting with awareness, i.e. attending to the present moment with awareness, as opposed to acting automatically (sample item: "I am easily distracted"; d) Non-judging: having a non-judgemental attitude towards one's inner experience (sample item: "I tell myself I shouldn't be feeling the way I'm feeling"); e) Non-reacting: allowing thoughts and emotions to come and go, without getting caught up in them or carried away by them (sample item: "In difficult situations, I can pause without immediately reacting"). The validity and reliability of FFMQ have been largely supported, indicating adequate and good internal consistency with alpha coefficients ranging from 0.72 to 0.92 (Baer et al., 2008; Christopher et al., 2012). Reliability coefficients from the current sample showed high internal consistency: Observing Cronbach's Alpha $=0.81$; Describing Cronbach's Alpha $=0.76$; Acting-withawareness Cronbach's Alpha $=0.70 ; \quad$ Non-judging Cronbach's Alpha $=0.90 ;$ Non-reacting Cronbach's Alpha $=0.74$.

\subsubsection{Beck Depression Inventory (BDI; Beck, 1967)}

The BDI is a 21-item self-report inventory used to measure symptoms of depression. Participants are asked to indicate which statement best describes their feelings over the past 7 days. (Sample item: "I feel the future is hopeless and that things cannot improve"). All responses are based on a four-point scale ranging from 0 to 3 . The total score is obtained by summing over the items, so that the higher the score, the higher the severity of depressive symptoms. Beck et al. (1988) reported a Cronbach's alpha value of 0.86 for psychiatric patients and 0.81 for non-psychiatric individuals. In our study, Cronbach's alpha for this measure was 0.86 .

\subsubsection{State-Trait Anxiety Scale (STAI-Y form Trait subscale; Spielberger, 1983)}

The STAI-Y form trait is a self-report inventory that measures trait anxiety. It consists of 20 items assessing trait anxiety (sample item: "I worry too much over something that really doesn't matter"). Responses are based on a 4-point Likert scale ranging from "not at all" to "extremely". The total score is obtained by summing over the items, so that the higher the score, the higher the severity of anxiety symptoms. Previous research has demonstrated high internal consistency (Cronbach's alpha above 0.90) (Spielberger, Gorsuch, \& Luschene, 1970; Spielberger \& Vagg, 1984). In this study, Cronbach's alpha was 0.93 .

\subsubsection{Penn State Worry Questionnaire (PSWQ; Meyer, Miller, Metzger, \& Borkovec, 1990)}

The PSWQ is a self-report measure assessing clinically significant worry. It consists of 16 items rated on a 5-point Likert-type scale, ranging from $1=$ not at all typical of me to $5=$ very typical of me (sample item: "I am always worrying about something"). The total score is obtained by summing over the items, so that the higher the score, the higher the severity of worry. In the original validation study (Meyer et al., 1990) Cronbach's alpha was 0.95. Cronbach's alpha in our sample was 0.74 .

\subsubsection{Ruminative Response Scale (RRS; Nolen-Hoeksema \& Morrow, 1991)}

The RRS is a self-report measure assessing the tendency to respond to depressed moods (sample item: "Think about all your shortcomings, failings, faults, mistakes"). The RRS consists of 22 items, all rated on a 4-point Likert-type scale, ranging from 1 (almost never) to 4 (almost always). In our study, we used the total score, obtained by summing all the responses so that higher scores correspond to higher rumination. The RSS is both a reliable and valid measure of rumination and several studies showed a Cronbach's alpha above 0.90 (Luminet, 2004; Roelofs, Muris, Huibers, Peeters, \& Arntz, 2006). Cronbach's alpha was 0.94 in this sample.

\section{Data analyses}

Prior to the main analyses, preliminary analyses were conducted to check data for underlying assumptions of normality and multicollinearity. In order to test the assumption of normality, we followed the following criteria, as suggested by Kline (2015): absolute skewness and kurtosis values lower than 3 and 8, respectively. To test multicollinearity, we examined correlations among variables, using a maximum correlation threshold of $|0.80|$ as an indicator of absence of multicollinearity (Field, 2009).

In order to conduct preliminary, bivariate and univariate analyses, we used the Statistical Package for Social Sciences (SPSS 23.0). Bivariate correlations were performed to assess the relationships among the five facets of mindfulness, anxiety, depression and the other variables of the study such as gender, age, worry and rumination. Next, two separate hierarchical multiple regressions were conducted to investigate the effects of mindfulness facets on anxiety and depression respectively, controlling for gender, age, worry and rumination. In particular, we decided to include worry and rumination because literature data show that anxiety is significantly and positively related to worry, and depression to rumination (Muris et al., 2005).

\section{Results}

4.1. Descriptive statistics and correlations among the facets of mindfulness and the other variables

Table 2 reports the values of skewness and kurtosis for all variables. Their values ranged from -0.45 and 1.25 for skewness and from -0.69 to 1.68 for kurtosis. Such results indicate that the assumption of normality was met. Table 2 also presents the bivariate correlations among gender, age, depression, anxiety, worry, rumination and the five facets of mindfulness (Observing, Describing, Acting-with-awareness, Non-judging, Non-reacting) for the overall group of participants. Correlations ranged from $r=|0.01|$ to $r=|0.73|$ at $p<.01$, indicating that multicollinearity was not an issue.

Results showed that worry is positively correlated both with depression $(r=0.46, p<.01)$ and anxiety $(r=0.66, p<.01)$, with moderate and large effect sizes, respectively. Findings indicated that also rumination is positively correlated both with depression $(r=0.55$, $p<.01)$, and anxiety $(r=0.55, p<.01)$, with large effect sizes.

Regarding the facets of mindfulness, all the subscales, except for Observing, were negatively correlated both with anxiety and depression scores, showing effect sizes that vary between -0.69 and 0.15 . The dimension of Non-judging showed large correlations both with anxiety $(r=-0.69, p<.01)$, and with depression $(r=-0.57, p<.01)$. However, also Acting-with-awareness had a large correlation both with anxiety $(r=-0.68, p<.01)$ and depression $(r=-0.57, p<.01)$.

A more detailed description of the bivariate correlations is provided in Table 2.

\subsection{Hierarchical regressions on anxiety and depression}

Using two separate hierarchical multiple regressions, we further examined how the facets of mindfulness could predict anxiety (Table 3) and depression (Table 4) scores, controlling for gender, age, worry and rumination. For both regressions, participants' gender and age were 
Table 2

Pearson's $r$ between the facets of mindfulness and the other variables of the study $(N=274)$.

\begin{tabular}{|c|c|c|c|c|c|c|c|c|c|c|c|c|}
\hline & 1 & 2 & 3 & 4 & 5 & 6 & 7 & 8 & 9 & 10 & 11 & 12 \\
\hline 1. Gender & 1.00 & & & & & & & & & & & \\
\hline 2. Age & -0.107 & 1.00 & & & & & & & & & & \\
\hline 3. Education level & $0.135^{*}$ & -0.010 & 1.00 & & & & & & & & & \\
\hline 4. BDI_Depression & 0.112 & 0.022 & $-0.187^{* * *}$ & 1.00 & & & & & & & & \\
\hline 5. STAI-Y_Anxiety & 0.075 & -0.098 & $-0.225^{* *}$ & $0.726^{* *}$ & 1.00 & & & & & & & \\
\hline 6. PSWQ_Worry & 0.113 & -0.060 & $-0.122^{*}$ & $0.465^{* *}$ & $0.659^{* * *}$ & 1.00 & & & & & & \\
\hline 7. RRS_Rumination & $0.160^{* * *}$ & $-0.127^{*}$ & $-0.121^{*}$ & $0.547^{* * *}$ & $0.546^{* *}$ & $0.450^{* * *}$ & 1.00 & & & & & \\
\hline 8. FFMQ_Observing & 0.079 & 0.124 & -0.083 & $0.152^{*}$ & 0.094 & 0.090 & $0.149 *$ & 1.00 & & & & \\
\hline 9. FFMQ_Describing & -0.008 & $0.143^{*}$ & 0.099 & $-0.137^{*}$ & $-0.197^{* *}$ & -0.129 & -0.081 & $0.306^{* *}$ & 1.00 & & & \\
\hline 10. FFMQ_Acting-with-awareness & -0.007 & 0.116 & $0.192^{* *}$ & $-0.478^{* *}$ & $-0.611^{* *}$ & $-0.503^{* *}$ & $-0.367^{* * *}$ & $-0.174^{* *}$ & $0.222^{* * *}$ & 1.00 & & \\
\hline 11. FFMQ_Non-judging & -0.044 & 0.038 & $0.250^{* *}$ & $-0.568^{* *}$ & $-0.681^{* *}$ & $-0.537^{* *}$ & $-0.521^{* *}$ & $-0.258^{* *}$ & 0.065 & $0.509^{* *}$ & 1.00 & \\
\hline 12. FFMQ_Non-reacting & -0.011 & 0.011 & 0.065 & $-0.166^{* *}$ & $-0.267^{* *}$ & $-0.250^{* *}$ & -0.114 & $0.439^{* *}$ & $0.325^{* * *}$ & 0.021 & 0.087 & 1.00 \\
\hline Mean & - & 34.50 & - & 10.50 & 43.84 & 44.62 & 64.08 & 24.57 & 24.95 & 25.29 & 28.87 & 20.88 \\
\hline Standard deviation & - & 10.25 & - & 7.95 & 11.04 & 14.06 & 13.11 & 5.85 & 5.12 & 5.17 & 6.79 & 4.35 \\
\hline Skewness & - & 1.25 & - & 0.96 & 0.35 & 0.22 & 0.18 & -0.17 & -0.45 & -0.41 & -0.38 & -0.12 \\
\hline Kurtosis & - & 1.68 & - & 0.40 & -0.51 & -0.69 & 0.99 & 0.02 & 0.11 & 0.29 & -0.45 & 0.56 \\
\hline
\end{tabular}

Note. Gender was coded as follows: Male $=1$; Female $=2$.

Education level was coded as follows: Middle school = 1; High school = 2; Bachelor degree = 3; Master degree $=4$; Postgraduate level $=5$.

${ }^{*} p<.05$.

** $p<.01$.

entered in the first step, whereas worry and rumination were entered in the second step. Finally, the five facets of mindfulness were entered in the third and last step.

Findings of the first regression on anxiety scores showed, as expected, that Non-judging was the strongest predictor of anxiety $(\beta=-0.33, S E=0.08, p<.001)$. Moreover, also Acting-with-awareness $(\beta=-0.26, S E=0.10, p<.001)$, and Non-reacting $(\beta=-0.14$, $S E=0.11, p=.001$ ), were negative and significant predictors of anxiety. Such results were obtained notwithstanding the significant effect of worry $(\beta=0.25, S E=0.04, p<.001)$ and the not-significant effect of gender, age, rumination and of the other two mindfulness facets (see Table 3). The $R^{2}$ for the whole model was $0.67(F=59.98, p<.001)$ and the variation of $R^{2}$, due to the last step with all the five facets of mindfulness was 0.15 . Findings of this regression analysis showed that individuals who are more likely to have anxiety symptoms are those ones who tend to worry more, who do not act with awareness, who judge and criticise themselves, their thoughts, and feelings, and who tend to react automatically to their inner experience.

As expected, findings of the second regression on depression scores showed that the Non-judging was the strongest predictor among the five facets of mindfulness $(\beta=-0.25, S E=0.07, p<.001)$. Again, Actingwith-awareness $(\beta=-0.20, S E=0.09, p<.001)$ was a negative and significant predictor of depression, while the other three mindfulness facets were not significant. Like the findings of the first regression, such results were obtained controlling for gender, age, worry and rumination (see Table 4). Specifically, rumination, and not worry, was a significant and positive predictor of depression $(\beta=0.29, S E=0.03, p<.001)$. The $R^{2}$ for the whole model was $0.47(F=23.69, p<.001)$ and the variation of $R^{2}$, due to the last step with the five facets of mindfulness was 0.09 . Findings of this second regression analysis indicate that individuals who ruminate, judge and criticise their inner experience and act without awareness are more likely to experience depression.

\section{Discussion}

The aim of the current study was to test the specific association between trait mindfulness and depression/anxiety controlling for the effects of gender, age, rumination, and worry. The results of bivariate correlation analyses showed moderate to large associations between rumination/worry and depression/anxiety. This evidence was consistent with several studies showing that rumination and worry are maladaptive cognitive coping strategies involved in the maintenance and exacerbation of depression and anxiety (Borkovec et al., 1983; Muris et al., 2005; Nolen-Hoeksema, 2000; Nolen-Hoeksema et al., 2008). With regard to trait mindfulness, bivariate correlation analyses indicated that Non-judging showed large and negative associations with rumination and worry: individuals who had stronger judgemental attitudes towards their inner experiences had also higher tendencies to rumination and worry. Acting-with-awareness showed a moderate negative association with rumination and a large negative association

Table 3

Hierarchical regression analyses for Gender, Age, PSWQ, RRS and FFMQ predicting STAI-Y scores.

\begin{tabular}{|c|c|c|c|c|c|c|c|}
\hline & $B$ & $S E B$ & $\beta$ & $F$ & $R^{2}$ & $\Delta R 2$ & $p$ \\
\hline Step 1 (identifying variables): & & & & 5.060 & 0.053 & 0.053 & 0.002 \\
\hline Gender & 0.087 & 0.892 & 0.004 & & & & 0.923 \\
\hline Age & -0.017 & 0.040 & -0.015 & & & & 0.677 \\
\hline Education level & 0.024 & 0.348 & 0.003 & & & & 0.964 \\
\hline Step 2 (Worry and Rumination): & & & & 58.420 & 0.522 & 0.468 & $<0.001$ \\
\hline PSWQ_Worry & 0.194 & 0.037 & $0.247 * *$ & & & & $<0.001$ \\
\hline RRS_Rumination & 0.128 & 0.037 & $0.152^{* *}$ & & & & 0.001 \\
\hline Step 3 (Facets of mindfulness): & & & & 52.977 & 0.668 & 0.147 & $<0.001$ \\
\hline FFMQ_Observing & -0.015 & 0.083 & -0.008 & & & & 0.861 \\
\hline FFMQ_Describing & -0.052 & 0.086 & -0.024 & & & & 0.551 \\
\hline FFMQ_Acting-with-awareness & -0.549 & 0.098 & $-0.257 * *$ & & & & $<0.001$ \\
\hline FFMQ_Non-judging & -0.530 & 0.080 & $-0.326^{* *}$ & & & & $<0.001$ \\
\hline FFMQ_NonReacting & -0.363 & 0.110 & $-0.143^{* *}$ & & & & 0.001 \\
\hline
\end{tabular}

Note. The tabled values for beta reflect $B$ s after step $3,{ }^{*} p<.05 ; * *<.01$. Gender was coded as follows: Male $=1$; Female $=2$.

Education level was coded as follows: Middle school $=1$; High school = 2; Bachelor degree $=3$; Master degree $=4$; Postgraduate level $=5$. 
Table 4

Hierarchical regression analyses for Gender, Age, PSWQ, RRS and FFMQ predicting BDI scores.

\begin{tabular}{|c|c|c|c|c|c|c|c|}
\hline & $B$ & $S E B$ & $\beta$ & $F$ & $R^{2}$ & $\Delta R 2$ & $p$ \\
\hline Step 1 (identifying variables): & & & & 7.04 & 0.073 & 0.073 & $<0.001$ \\
\hline Gender & 1.124 & 0.809 & 0.065 & & & & 0.166 \\
\hline Age & 0.080 & 0.036 & $0.103^{*}$ & & & & 0.028 \\
\hline Education level & -0.529 & 0.316 & -0.079 & & & & 0.095 \\
\hline Step 2 (Worry and Rumination): & & & & 34.05 & 0.388 & 0.316 & $<0.001$ \\
\hline PSWQ_Worry & 0.035 & 0.034 & 0.062 & & & & 0.295 \\
\hline RRS_Rumination & 0.178 & 0.033 & $0.294 * *$ & & & & $<0.001$ \\
\hline Step 3 (Facets of mindfulness): & & & & 23.69 & 0.474 & 0.085 & $<0.001$ \\
\hline FFMQ_Observing & 0.040 & 0.075 & 0.030 & & & & 0.592 \\
\hline FFMQ_Describing & -0.050 & 0.078 & -0.032 & & & & 0.523 \\
\hline FFMQ_Acting-with-awareness & -0.301 & 0.089 & $-0.195^{* *}$ & & & & $<0.001$ \\
\hline FFMQ_Non-judging & -0.289 & 0.072 & $-0.247^{* *}$ & & & & $<0.001$ \\
\hline FFMQ_Non-reacting & -0.163 & 0.100 & -0.089 & & & & 0.103 \\
\hline
\end{tabular}

Note. The tabled values for beta reflect $B$ s after step $3,{ }^{*} p<.05 ; * * p<.01$. Gender was coded as follows: Male $=1$; Female $=2$.

Education level was coded as follows: Middle school = 1; High school = 2; Bachelor degree = 3; Master degree $=4$; Postgraduate level = 5.

with worry. These results are in line with previous research conducted in clinical samples (Coffey et al., 2010; Desrosiers et al., 2013). Describing and Non-reacting showed weak negative associations with both rumination and worry; conversely, Observing showed a weak positive association with these cognitive processes, suggesting that individuals who tend to observe their feelings and thoughts, also tend to worry and ruminate to a greater extent. This finding is consistent with previous data suggesting that those individuals who tend to observe their external/inner experience have a higher tendency to ruminate and worry (Royuela-Colomer \& Calvete, 2016). This means that being capable of observing one's thoughts and feelings is neither tantamount to accepting them, nor is in itself beneficial, unless an accepting and nonjudgemental stance is also present: previous research showed that the mere act of observing one's inner states can be associated with an increase in negative emotions (Petrocchi \& Ottaviani, 2016).

Consistent with previous data in the literature (Baer et al., 2006; Barnhofer et al., 2011), Non-judging and Acting-with-awareness showed large associations with depression and anxiety: individuals with low trait mindfulness, particularly those who tend to judge themselves, to criticise their feelings and beliefs and to act automatically instead of acting with awareness, have higher depression and anxiety levels.

Subsequently, regression analyses were conducted to test the specific contribution of each trait mindfulness facet on depression or anxiety, controlling for the effects of gender, age, worry and rumination. Worry and rumination significantly and positively predicted anxiety, indicating that individuals who tend to adopt these coping strategies tend to be more anxious. These data support the role of rumination and worry as maintenance mechanisms involved in anxiety, as demonstrated by a large amount of previous data (e.g., Muris et al., 2005; Nolen-Hoeksema, 2000; Raes, 2010), and as formulated by well-established theoretical models of anxiety (e.g., Borkovec et al., 1983). Rumination, but not worry, significantly predicted depressive features, suggesting that this is one of the main cognitive strategies associated with depressive symptomatology, a result in line with previous research showing that this cognitive process is associated with depression and, to a lesser extent, with anxiety (Raes, 2010). Consistent with some studies, rumination could be hypothesised to be a transdiagnostic style of repetitive thinking associated with depression and anxiety (Segerstrom, Tsao, Alden, \& Craske, 2000).

The results of the regression analyses show that Non-judging is the mindfulness facet most predictive of both depression and anxiety. However, the results of the regression analyses showed that also the capacity to act with awareness is a meaningful mindfulness feature, highly associated with both depression and anxiety. In addition, Nonreacting predicts anxiety. Conversely, Describing and Observing did not result to predict significantly depression and anxiety. This evidence was consistent with the findings in Cash and Whittingham (2010).
The idea that harsh criticism towards one's own negative feelings and thoughts exacerbates psychological problems has long been shared by the cognitive-behavioural tradition: Ellis $(1986,1987)$ distinguished between primary and secondary problems. "Secondary problems" involve the tendency to negatively judge and be intolerant to any kind of negative thought, feeling or affect. The association between judgement and depression is coherent with valid and sound cognitive theories of depression, in which self-criticism plays a pivotal role, while acceptance and self-warmth are related to wellbeing (Gilbert, Baldwin, Irons, Baccus, \& Palmer, 2006). When individuals criticise themselves and their feelings, thoughts, and emotions, they experience higher levels of suffering. Such self-criticism, far from being helpful in getting rid of negative moods and beliefs, exacerbates the very same negative thoughts and emotions that they are experiencing (Barcaccia \& Couyoumdjian, 2018; De Silvestri, 2000; Ellis, 1986, 1987; Gardner, Mancini, \& Semerari, 1988).

An interesting clinical implication of our results might regard the role of psychologists and other mental health professionals in "normalising" the patients' experience of negative thinking and feeling: selfcriticism and negative self-judgement is such a relevant mechanism of maintenance of suffering, that it is considered preferable to address it before any other (primary) problem, at the beginning of therapy (De Silvestri, 2000), in order to alleviate the judgemental attitude, responsible of maintaining and exacerbating those negative cognitive and emotional features. Even in the initial phase of assessment, psychologists, psychiatrists and psychotherapists could help patients normalise and accept their negative thoughts, mental images, feelings, and emotions, a goal that could be achieved by both classical cognitive restructuring interventions and by mindfulness-based practices. This apparently simple intervention has the potential to defuse one of the most powerful mechanism in the maintenance of suffering: self-judgement (Rimes \& Watkins, 2005; Tesh, Learman, \& Pulliam, 2015).

Our study presents some limitations. First of all, it includes a convenience sample of non-clinical individuals, which limits the generalisability of the findings. Future research could focus also on clinical samples, to better investigate the role of mindfulness facets in predicting both anxiety and depression. Second, our study relied on selfreport measures. Although self-report measures are considered a valid and reliable evaluation of inner feelings and thoughts, future studies could add another source of assessment, such as structured questionnaires administered by mental health professionals. In addition, the cross-sectional design prevents us from drawing conclusion about the causal link between trait mindfulness and depression/anxiety. Future studies could also explore other variables potentially mediating or moderating the association between mindfulness and depression/anxiety.

Future process/outcome research on MBIs could include rumination 
and worry measures as outcomes, in order to investigate the clinical mechanisms of change involved in those interventions. It could be interesting to test whether changes in Non-judging and Non-reacting are associated to changes in rumination/worry in depression/anxiety.

\section{Conclusions}

Our findings, regarding the association among the disposition to negatively label and evaluate one's own inner feelings and thoughts with anxiety and depression, highlight the importance of a normalising, accepting and non-judgemental attitude for the wellbeing of individuals. When individuals criticise themselves and their inner experience, they go through higher levels of suffering. Self-criticism aggravates the suffering associated to negative moods and beliefs (De Silvestri, 2000; Ellis, 1986, 1987; Gardner et al., 1988).

Although it cannot be generalised to clinical groups, the relation among the judgemental attitude and anxiety/depression in a non-clinical sample suggests the benefits of a mindful, self-accepting and nonjudgemental stance as instruments of prevention and/or low-intensity intervention (Sundquist et al., 2015). In conclusion, our study highlights the importance of a normalising, accepting and non-judgemental attitude to decrease anxiety and depression and to enhance wellbeing.

\section{Declarations of interest}

None.

All authors declare that they have no conflict of interest.

\section{References}

Baer, R. A. (2003). Mindfulness training as a clinical intervention: Conceptual and empirical review. Clinical Psychology: Science and Practice, 10, 125-143. https://doi.org/ 10.1093/clipsy/bpg015.

Baer, R. A., Smith, G. T., Hopkins, J., Krietemeyer, J., \& Toney, L. (2006). Using selfreport assessment methods to explore facets of mindfulness. Assessment, 13, 27-45. https://doi.org/10.1177/1073191105283504.

Baer, R. A., Smith, G. T., Lykins, E., Button, D., Kreitemeyer, J., Sauer, ... Williams, J. (2008). Construct validity of the five facet mindfulness questionnaire in meditating and nonmeditating samples. Assessment, 15, 329-342. https://doi.org/10.1177/ 1073191107313003.

Barcaccia, B., \& Couyoumdjian, A. (2018). Mindfulness for the treatment of obsessivecompulsive disorder. In F. Mancini (Ed.). The obsessive mind: Understanding and treating obsessive-compulsive disorder (pp. 275-296). New York: Routledge.

Barnhofer, T., Duggan, D. S., \& Griffith, J. W. (2011). Dispositional mindfulness moderates the relation between neuroticism and depressive symptoms. Personality and Individual Differences, 51, 958-962. https://doi.org/10.1016/j.paid.2011.07.032.

Beck, A. T. (1967). Depression: Clinical, experimental, and theoretical aspects. University of Philadelphia: Pennsylvania Press.

Beck, A. T., Steer, R. A., \& Carbin, M. G. (1988). Psychometric properties of the Beck Depression Inventory: Twenty-five years of evaluation. Clinical Psychology Review, 8, 77-100. https://doi.org/10.1016/0272-7358(88)90050-5.

Borkovec, T. D., Robinson, E., Pruzinsky, T., \& DePree, J. A. (1983). Preliminary exploration of worry: Some characteristics and processes. Behaviour Research and Therapy, 21, 9-16. https://doi.org/10.1016/0005-7967(83)90121-3.

Bränström, R., Duncan, L. G., \& Moskowitz, J. T. (2011). The association between dispositional mindfulness, psychological well-being, and perceived health in a Swedish population-based sample. British Journal of Health Psychology, 16, 300-316. https:// doi.org/10.1348/135910710X501683.

Brown, K. W., \& Ryan, R. M. (2003). The benefits of being present: Mindfulness and its role in psychological well-being. Journal of Personality and Social Psychology, 84, 822-848.

Cash, M., \& Whittingham, K. (2010). What facets of mindfulness contribute to psychological well-being and depressive, anxious, and stress-related symptomatology? Mindfulness, 1, 177-182. https://doi.org/10.1007/s12671-010-0023-4.

Christopher, M. S., Neuser, N. J., Michael, P. G., \& Baitmangalkar, A. (2012). Exploring the psychometric properties of the five facet mindfulness questionnaire. Mindfulness, 3, 124-131. https://doi.org/10.1007/s12671-011-0086-x.

Coffey, K., Hartman, M., \& Fredrickson, B. L. (2010). Deconstructing mindfulness and constructing mental health: Understanding mindfulness and its mechanisms of action. Mindfulness, 1, 235-253.

De Silvestri, C. (2000). Il ruolo dell'attenzione nella teoria e nella prassi della psicoterapia RET [the role of attention in the RET theory and practice]. Informazione Psicologia Psicoterapia Psichiatria, 39, 70-83.

Delgado, L. C., Guerra, P., Perakakis, P., Vera, M. N., del Paso, G. R., \& Vila, J. (2010) Treating chronic worry: Psychological and physiological effects of a training programme based on mindfulness. Behaviour Research and Therapy, 48, 873-882. https:// doi.org/10.1016/j.brat.2010.05.012

Desrosiers, A., Vine, V., Klemanski, D. H., \& Nolen-Hoeksema, S. (2013). Mindfulness and emotion regulation in depression and anxiety: Common and distinct mechanisms of action. Depression and Anxiety, 30, 654-661. https://doi.org/10.1002/da.22124.

Dundas, I., Vøllestad, J., Binder, P.-E., \& Sivertsen, B. (2013). The five factor mindfulness questionnaire in Norway. Scandinavian Journal of Psychology, 54(3), 250-260. https://doi.org/10.1111/sjop.12044.

Ellis, A. (1986). Discomfort anxiety: A new cognitive behavioral construct. In A. Ellis, \& R. M. Grieger (Vol. Eds.), Handbook of rational-emotive therapy. Vol. 2. Handbook of rational-emotive therapy (pp. 105-120). New York: Springer.

Ellis, A. (1987). A sadly neglected cognitive element in depression. Cognitive Therapy and Research, 11, 121-145.

Field, A. (2009). Discovering statistics using SPSS. Sage publications.

Gardner, G. G., Mancini, F., \& Semerari, A. (1988). Construction of psychological disorders as invalidation of self-knowledge. In F. Fransella, \& L. F. Thomas (Eds.). Experimenting with personal construct psychology (pp. 259-272). New York, NY: Routledge.

Gilbert, P., Baldwin, M. W., Irons, C., Baccus, J. R., \& Palmer, M. (2006). Self-criticism and self-warmth: An imagery study exploring their relation to depression. Journal of Cognitive Psychotherapy, 20, 183-200. https://doi.org/10.1891/jcop.20.2.183.

Gu, J., Strauss, C., Bond, R., \& Cavanagh, K. (2015). How do mindfulness-based cognitive therapy and mindfulness-based stress reduction improve mental health and wellbeing? A systematic re-view and meta-analysis of mediation studies. Clinical Psychology Review, 37, 1-12. https://doi.org/10.1016/j.cpr.2015.01.006.

Hayes, S. C., \& Greco, L. A. (2008). Acceptance and mindfulness for youth: It's time. In L. Greco (Ed.). Acceptance and mindfulness treatments for children and adolescents: A practitioner' guide (pp. 3-13). Oakland, CA: New Harbinger.

Hofmann, S. G., Sawyer, A. T., Witt, A. A., \& Oh, D. (2010). The effect of mindfulnessbased therapy on anxiety and depression: A meta-analytic review. Journal of Consulting and Clinical Psychology, 78, 169-183. https://doi.org/10.1037/a0018555.

Jain, S., Shapiro, S., Swanick, S., Roesch, S. C., Mills, P. J., Bell, I., \& Schwatrz, G. E. R. (2007). A randomized controlled trial of mindfulness meditation versus relaxation training: Effects on distress, positive states of mind, rumination, and distraction. Annals of Behavioral Medicine, 33, 11-21. https://doi.org/10.1207/ s15324796abm3301_2.

Jennings, J., \& Apsche, J. (2013). The youth companion to the mindfulness toolkit. Holyoke, MA: NEARI Press.

Kabat-Zinn, J. (1982). An outpatient program in behavioral medicine for chronic pain patients based on the practice of mindfulness meditation: Theoretical considerations and preliminary results. General Hospital Psychiatry, 4, 33-47. https://doi.org/10. 1016/0163-8343(82)90026-3.

Kabat-Zinn, J. (1994). Wherever you go, there you are: Mindfulness meditation for everyday life. New York: Hyperion.

Kallapiran, K., Koo, S., Kirubakaran, R., \& Hancock, K. (2015). Review: Effectiveness of mindfulness in improving mental health symptoms of children and adolescents: A meta-analysis. Child and Adolescent Mental Health, 20, 182-194. https://doi.org/10. 1111 /camh.12113.

Khoury, B., Lecomte, T., Fortin, G., Masse, M., Therien, P., Bouchard, V., ... Hofmann, S. G. (2013). Mindfulness-based therapy: A comprehensive meta-analysis. Clinical Psychology Review, 33, 763-771. https://doi.org/10.1016/j.cpr.2013.05.005.

Khoury, B., Sharma, M., Rush, S. E., \& Fournier, C. (2015). Mindfulness-based stress reduction for healthy individuals: A meta-analysis. Journal of Psychosomatic Research, 78, 519-528. https://doi.org/10.1016/j.jpsychores.2015.03.009.

Kline, R. B. (2015). Principles and practice of structural equation modelling. London: Guilford Publications.

Kong, F., Wang, X., \& Zhao, J. (2014). Dispositional mindfulness and life satisfaction: The role of core self-evaluations. Personality and Individual Differences, 56, 165-169.

Kopala-Sibley, D. C., Zuroff, D. C., Hankin, B. L., \& Abela, J. R. (2015). The development of self-criticism and dependency in early adolescence and their role in the development of depressive and anxiety symptoms. Personality and Social Psychology Bulletin, 41(8), 1094-1109.

Kumar, S., Feldman, G., \& Hayes, A. (2008). Changes in mindfulness and emotion regulation in an exposure-based cognitive therapy for depression. Cognitive Therapy \& Research, 32(6), 734-744. https://doi.org/10.1007/s10608-008-9190-1.

Luminet, O. (2004). Measurement of depressive rumination and associated constructs. In C. Papageorgiou, \& A. Wells (Eds.). Depressive rumination. Nature, theory and treatment (pp. 187-215). Chichester: Wiley.

Malinowski, P., \& Lim, H. J. (2015). Mindfulness at work: Positive affect, hope, and optimism mediate the relationship between dispositional mindfulness, work engagement, and well-being. Mindfulness, 6(6), 1250-1262. https://doi.org/10.1007/ s12671-015-0388-5.

Meyer, T. J., Miller, M. L., Metzger, R. L., \& Borkovec, T. D. (1990). Development and validation of the Penn State Worry Questionnaire. Behaviour Research and Therapy, 28, 487-495. https://doi.org/10.1016/0005-7967(90)90135-6.

Muris, P., Roelofs, J., Rassin, E., Franken, I., \& Mayer, B. (2005). Mediating effects of rumination and worry on the links between neuroticism, anxiety and depression. Personality and Individual Differences, 39, 1105-1111. https://doi.org/10.1016/j.paid. 2005.04.005.

Nolen-Hoeksema, S. (2000). The role of rumination in depressive disorders and mixed anxiety/depressive symptoms. Journal of Abnormal Psychology, 109, 504-511. https://doi.org/10.1037/0021-843X.109.3.504.

Nolen-Hoeksema, S., \& Morrow, J. (1991). A prospective study of depression and posttraumatic stress symptoms after a natural disaster: The 1989 Loma Prieta earthquake. Journal of Personality and Social Psychology, 61, 115-121.

Nolen-Hoeksema, S., Wisco, B. E., \& Lyubomirsky, S. (2008). Rethinking rumination. Perspectives on Psychological Science, 3, 400-424. https://doi.org/10.1111/j.1745- 
6924.2008.00088.x

Petrocchi, N., \& Ottaviani, C. (2016). Mindfulness facets distinctively predict depressive symptoms after two years: The mediating role of rumination. Personality and Individual Differences, 93, 92-96. https://doi.org/10.1016/j.paid.2015.08.017.

Raes, F. (2010). Rumination and worry as mediators of the relationship between selfcompassion and depression and anxiety. Personality and Individual Differences, 48 , 757-761. https://doi.org/10.1016/j.paid.2010.01.023.

Raes, F., \& Williams, M. G. (2010). The relationship between mindfulness and uncontrollability of ruminative thinking. Mindfulness, 1, 199-203. https://doi.org/10. 1007/s12671-010-0021-6.

Rimes, K. A., \& Watkins, E. (2005). The effects of self-focused rumination on global negative self-judgements in depression. Behavior Research and Therapy, 43, 1673-1681. https://doi.org/10.1016/j.brat.2004.12.002.S0005-7967(05)00018-5.

Roelofs, J., Muris, P., Huibers, M., Peeters, F., \& Arntz, A. (2006). On the measurement of rumination: A psychometric evaluation of the ruminative response scale and the rumination on sadness scale in undergraduates. Journal of Behavior Therapy and Experimental Psychiatry, 37, 299-313. https://doi.org/10.1016/j.jbtep.2006.03.002.

Royuela-Colomer, E., \& Calvete, E. (2016). Mindfulness facets and depression in adolescents: Rumination as a mediator. Mindfulness, 7, 1092-1102.

Segerstrom, S. C., Tsao, J. C., Alden, L. E., \& Craske, M. G. (2000). Worry and rumination: Repetitive thought as a concomitant and predictor of negative mood. Cognitive Therapy and Research, 24, 671-688. https://doi.org/10.1023/A:1005587311498.

Shapiro, S. L., Carlson, L. E., Astin, J. A., \& Freedman, B. (2006). Mechanisms of mind fulness. Journal of Clinical Psychology, 62, 373-386. https://doi.org/10.1002/jclp. 20237.

Singh, S. K., \& Gorey, K. M. (2017). Relative effectiveness of mindfulness and cognitive behavioral interventions for anxiety disorders: Meta-analytic review. Social Work in Mental Health, 1-14. https://doi.org/10.1080/15332985.2017.1373266.

Spielberger, C. D. (1983). Manual for the state-trait anxiety inventory (form Y). Palo Alto, California: Consulting Psychologists Press.
Spielberger, C. D., Gorsuch, R. L., \& Luschene, R. (1970). Test manual for the state- trait anxiety inventory. Palo Alto, CA: Consulting Psychologists Press.

Spielberger, C. D., \& Vagg, P. R. (1984). Psychometric properties of the STAI: A reply to Ramanaiah, Franzen, and Schill. Journal of Personality Assessment, 48(1), 95-97. https://doi.org/10.1207/s15327752jpa4801_16.

Sundquist, J., Lilja, Å., Palmér, K., Memon, A. A., Wang, X., Johansson, L. M., et al. (2015). Mindfulness group therapy in primary care patients with depression, anxiety and stress and adjustment disorders: Randomised controlled trial. British Journal of Psychiatry, 206, 128-135. https://doi.org/10.1192/bjp.bp.114.150243.

Teasdale, J. D., Segal, Z., \& Williams, J. G. (1995). How does cognitive therapy prevent depressive relapse and why should attentional control (mindfulness) training help? Behaviour Research \& Therapy, 33(1), 25-39. https://doi.org/10.1016/0005-7967(94) e0011-7.

Tesh, M., Learman, J., \& Pulliam, R. M. (2015). Mindful self-compassion strategies for survivors of intimate partner abuse. Mindfulness, 6, 192-201. https://doi.org/10. 1007/s12671-013-0244-4.

Van der Velden, A. M., Kuyken, W., Wattar, U., Crane, C., Pallesen, K. J., Dahlgaard, J., .. Piet, J. (2015). A systematic review of mechanisms of change in mindfulness-based cognitive therapy in the treatment of recurrent major depressive disorder. Clinical Psychology Review, 37, 6-39. https://doi.org/10.1016/j.cpr.2015.02.001.

Warren, F., Kuyken, W., Taylor, R., Whalley, B., Crane, C., Bondolfi, G., ... Schwelzer, S. (2016). Efficacy and moderators of mindfulness-based cognitive therapy (MBCT) in prevention of depressive relapse: An individual patient data meta-analysis from randomized trials. JAMA Psychiatry, 73(6), 565-574. https://doi.org/10.1001/ jamapsychiatry.2016.0076.

World Medical Association (2013). WMA Declaration of Helsinki-Ethical Principles for Medical Research Involving Human Subjects (2013). Retrieved from: https://www. wma.net/policies-post/wma-declaration-of-helsinki-ethical-principles-for-medicalresearch-involving-human-subjects/, Accessed date: 1 September 2018. 